\title{
Development of a Novel Highly Spontaneous Metastatic Model of Esophageal Squamous Cell Carcinoma Using Renal Capsule Technology
}

This article was published in the following Dove Press journal: OncoTargets and Therapy

\author{
Pan Gao ${ }^{1,2, *}$ \\ Hongtao Liu ${ }^{3, *}$ \\ Zhenzhen Yang ${ }^{1,2}$ \\ Yiran $\mathrm{Hui}^{2,4}$ \\ Zhuangzhuang Shi ${ }^{2}$ \\ Zhen Yang ${ }^{2}$ \\ Min Song ${ }^{2}$ \\ Menghui Yao ${ }^{2}$ \\ Wenfei Fan' \\ Jinhua Yang' \\ Yibin Hao' \\ Tianli Fan ${ }^{2}$ \\ 'People's Hospital of Zhengzhou, \\ Zhengzhou, Henan, 45000I, People's \\ Republic of China; ${ }^{2}$ Department of \\ Pharmacology, School of Basic Medicine, \\ Zhengzhou University, Zhengzhou, \\ Henan, 45000I, People's Republic of \\ China; ${ }^{3}$ Laboratory for Cell Biology, \\ College of Life Sciences of Zhengzhou \\ University, Zhengzhou, Henan, 45000I, \\ People's Republic of China; ${ }^{4}$ University of \\ Chinese Academy of Sciences-Shenzhen \\ Hospital, Shenzhen, Guangdong, 518106, \\ People's Republic of China
}

*These authors contributed equally to this work
Correspondence: Tianli Fan

Department of Pharmacology, School of Basic Medicine, Zhengzhou University,

Zhengzhou, Henan, 45000I, People's

Republic of China

Email fantianli@zzu.edu.cn
Purpose: Increasing evidence has demonstrated that animal models are imperative to investigate the potential molecular mechanism of metastasis and discover anti-metastasis drugs; however, efficient animal models to unveil the underlying mechanisms of metastasis in esophageal squamous cell carcinoma (ESCC) are limited.

Methods: ESCC cell EC9706 with high invasiveness was screened by repeated Transwell assays. Its biological characteristics were identified by flow cytometry as well as by the wound healing and CCK-8 assays. Besides, the levels of epithelial-mesenchymal transitionrelated markers were examined using Western blotting. Parental (EC9706-I ${ }_{0}$ ) and subpopulation (EC9706-I $\mathrm{I}_{3}$ ) cells were employed to establish the renal capsule model. Next, the tumor growth was detected by a live animal imaging system, and hematoxylin and eosin staining was applied to evaluate the metastatic status in ESCC.

Results: EC9706- $\mathrm{I}_{3}$ cells showed rapid proliferation ability, S phase abundance, and high invasive ability; obvious upregulation in N-cadherin, Snail, Vimentin, and Bit1; and downregulation in E-cadherin. EC9706- $\mathrm{I}_{3}$ cells were less sensitive to the chemotherapy drug 5-fluorouracil than EC9706- $\mathrm{I}_{0}$ cells; however, both cell lines reached a tumorigenesis rate of $100 \%$ in the renal capsule model. The live animal imaging system revealed that the tumors derived from EC9706- $\mathrm{I}_{0}$ cells grew more slowly than those from EC9706- $\mathrm{I}_{3}$ cells at weeks 3-14. The EC9706- $\mathrm{I}_{3}$ xenograft model displayed a spontaneous metastatic site, including kidney, heart, liver, lung, pancreas, and spleen, with a distant metastatic rate of $80 \%$.

Conclusion: Our data suggested that the metastatic model was successfully established, providing a novel platform for further exploring the molecular mechanisms of metastasis in ESCC patients.

Keywords: esophageal squamous cell carcinoma, renal capsule model, spontaneous metastasis, epithelial-mesenchymal transition process

\section{Introduction}

Esophageal squamous cell carcinoma (ESCC) is one of the most common digestive tumors that seriously affect human health. ${ }^{1-3}$ Metastasis from the primary foci to distant organs is a common cause of death in most patients with ESCC since it hinders the timely diagnosis and application of treatment protocols. ${ }^{4}$ The 5 -year survival rate of metastatic ESCC patients remains elusive, ${ }^{5}$ probably due to the lack of an efficient animal model for evaluating anti-metastasis drugs. Therefore, it is essential to develop novel animal models to unveil the underlying molecular mechanisms of ESCC and discover effective anti-metastasis drugs. 
The establishment of novel animal models helps to bridge gaps between basic and clinical cancer research. ${ }^{6}$ Previous reports revealed that novel therapeutic strategies were developed prior to clinical treatment protocols using mouse models for esophageal cancer. ${ }^{7-11}$ To date, the reported esophageal cancer metastasis models, such as the intravenous and intracardiac injection, ${ }^{12-15}$ the orthotopic, ${ }^{16}$ and subcutaneous xenograft, ${ }^{15,17}$ as well as the Levrat model, ${ }^{18}$ have several key limitations. For instance, several models fail in the steps of full metastatic cascade including dissemination of cancer cells from the primary tumor, lead to complications and high mortality, or have long duration and poor reproducibility. ${ }^{19}$ Therefore, it is imperative to develop novel metastatic ESCC models to further assess the efficacy of antitumor drugs and, consequently, improve the therapeutic outcome.

In this study, to study the mechanism of ESCC metastasis, we screened and characterized the ESCC cell line harboring highly metastatic potential using EC9706 cells as parental cell line, which derived from poorly differentiated esophageal squamous cell carcinoma. ${ }^{20} \mathrm{~A}$ spontaneous animal model was established using renal capsule technology, and the metastatic status was investigated by hematoxylin and eosin staining. Our data provided a promising platform for further exploring the molecular mechanisms underlying ESCC.

\section{Materials and Methods}

\section{Cell Line and Culture}

The parental human ESCC cell line EC9706 (EC9706- $\mathrm{I}_{0}$ ) was obtained from the Tumor Cell Bank of the Chinese Academy of Sciences and cultured in RPMI 1640 medium (Solarbio Life Sciences, Beijing, China), supplemented with $10 \%$ Newborn bovine serum (BI), penicillin, and streptomycin, in a humidified atmosphere of $5 \%$ carbon dioxide $\left(\mathrm{CO}_{2}\right)$ at $37^{\circ} \mathrm{C}$.

\section{Transwell Assay}

Transwell assay (Corning Life Sciences, Tewksbury, MA, USA) was used to screen the subpopulation of EC9706 cells with high invasive ability (EC9706- $\mathrm{I}_{3}$ ). Briefly, a total of $5 \times 10^{5}$ cells were seeded in a top chamber and coated with $100 \mu \mathrm{L}$ of Matrigel (1:6; BD Biosciences, San Jose, CA, CA), whereas $600 \mu \mathrm{L}$ of 1640 medium, containing $20 \%$ fetal bovine serum (FBS), was added to the lower chamber as a chemoattractant. After incubation for $48 \mathrm{~h}$ at $37^{\circ} \mathrm{C}$, the cells remaining in the top chamber were scraped off with a cotton swab. Subsequently, the invasive cells were trypsinized and cultured in RPMI 1640 medium with $10 \%$ Newborn bovine serum at $37^{\circ} \mathrm{C}$. The cells were then passaged and frozen for a second round of screening. The above procedure was performed in triplicate.

\section{Cell Viability and Proliferation Assays}

Cell viability was assessed by the CCK- 8 assay. Cells were seeded in $100 \mu \mathrm{L}$ of culture medium at a density of $5 \times 10^{3}$ cells well ${ }^{-1}$ in 96-well plates and cultured for $24 \mathrm{~h}$ at $37^{\circ} \mathrm{C}$. Then, $100 \mu \mathrm{L}$ of culture medium, containing 5-fluorouracil (5-FU; Hanson Pharma, China), doxorubicin (ADM; Hisun Pharma, China), and cisplatin (DDP; SunRise Pharma, China), was added in each well. The concentrations of 5-FU were $0.0 \mu \mathrm{g}, 0.1 \mu \mathrm{g}, 0.2 \mu \mathrm{g}, 0.4 \mu \mathrm{g}, 0.8 \mu \mathrm{g}, 1.6 \mu \mathrm{g}$, $3.2 \mu \mathrm{g}, 6.4 \mu \mathrm{g}, 12.8 \mu \mathrm{g}$, or $25.6 \mu \mathrm{g}$, whereas those of ADM and DDP were $0.00 \mu \mathrm{g}, 0.02 \mu \mathrm{g}, 0.04 \mu \mathrm{g}, 0.08 \mu \mathrm{g}, 0.16 \mu \mathrm{g}$, $0.32 \mu \mathrm{g}, 0.64 \mu \mathrm{g}, 1.28 \mu \mathrm{g}, 2.56 \mu \mathrm{g}$, or $5.12 \mu \mathrm{g}$. Each concentration was repeated in triplicate. At $72 \mathrm{~h}$ post-culturing with 5-FU and $48 \mathrm{~h}$ with ADM and DDP, the medium was discarded and replaced with $8 \mu \mathrm{L}$ of CCK- 8 solution (Beyotime, Shanghai, China) and $92 \mu \mathrm{L}$ of 1640 medium. The cells were incubated for $2 \mathrm{~h}$ at $37^{\circ} \mathrm{C}$, and then the absorbance was determined at $450 \mathrm{~nm}$ using a microplate reader (Bio-tek, Winooski, VT, USA).

Cell proliferation was also assessed by the CCK-8 assay. Briefly, cells were seeded in $100 \mu \mathrm{L}$ of culture medium at a density of $2 \times 10^{3}$ cells well $^{-1}$ in 96 -well plates and cultured for $24 \mathrm{~h}$ at $37^{\circ} \mathrm{C}$. Next, CCK- 8 reagents were added to each well at $0 \mathrm{~h}, 24 \mathrm{~h}, 48 \mathrm{~h}$ and $96 \mathrm{~h}$ post-culture. The detection steps were as described above.

\section{Flow Cytometry Assay}

Parental (EC9706- $\left.\mathrm{I}_{0}\right)$ and subpopulation (EC9706- $\mathrm{I}_{3}$ ) cells were collected using trypsin during the exponential growth phase. The cells were rinsed three times with pre-chilled phosphate-buffered saline (PBS), centrifuged at $2000 \mathrm{rpm}$ for $5 \mathrm{~min}$, and suspended in a tube at a density of $1 \times 10^{6}$ cells $\mathrm{mL}^{-1}$. Then, the cells were fixed with $70 \%$ ethanol overnight at $4{ }^{\circ} \mathrm{C}$. The fixed cells were centrifuged and resuspended in $500 \mathrm{~mL}$ of sample staining buffer, containing $25 \mathrm{~mL}$ propidium iodide and $10 \mathrm{~mL}$ RNase A. The cells were incubated for $30 \mathrm{~min}$ at $37^{\circ} \mathrm{C}$ in the dark, and then, the variation in the DNA content was detected using a flow cytometer (Beckman Coulter, Brea, CA, USA).

\section{Wound Healing Assay}

EC9706 cells were inoculated at a density of $5 \times 10^{5}$ cells well $^{-1}$ in 6-well culture plates (Corning Life Sciences). The cells 
reached an 80-85\% confluence, and the scarring cell monolayers of EC9706 were then scraped with a sterile 200- $\mu \mathrm{L}$ pipette tip. After rinsing twice with PBS to remove the suspended cells and debris, ESCC cells were cultured in a fresh medium with $2 \%$ FBS. Images of each well were acquired immediately using a Nikon Eclipse TS100 microscope (Nikon, Tokyo, Japan). Cells were cultured for $24 \mathrm{~h}, 48 \mathrm{~h}$ and $72 \mathrm{~h}$ at $37^{\circ} \mathrm{C}$. The degree of cell spread among groups was quantified by measuring the distances from the wound edges.

\section{Western Blot}

Cells were lysed by adding RIPA lysis buffer supplemented with a protease inhibitor (Phenylmethanesulfonyl fluoride; Solarbio Life Sciences, Beijing, China) and the phosphatase inhibitor Na3VO4 (Beyotime, Shanghai, China). Cell lysates were centrifuged at $15,000 \mathrm{rpm}$ for $10 \mathrm{~min}$ at $4^{\circ} \mathrm{C}$. Approximately $0.4 \mathrm{mg}$ of protein was mixed with $4 \times$ protein sample buffer and heated for 5 min at $100^{\circ} \mathrm{C}$. Samples were separated by $8-15 \%$ sodium dodecyl sulfate-polyacrylamide gel electrophoresis and transferred onto a polyvinylidene fluoride membrane for incubating with the corresponding antibodies ( $\mathrm{N}$-cadherin,
E-cadherin, Vimentin, Snail, Bit1 or $\beta$-actin; Abcam, Cambridge, MA, USA) for overnight at $4^{\circ} \mathrm{C}$, and then with secondary antibodies (Abcam) for $2 \mathrm{~h}$ at $37^{\circ} \mathrm{C}$. The protein bands were visualized using the enhanced chemiluminescent detection system (Beyotime Biotech, Shanghai, China), whereas the relative protein level using AlphaView (Protein Simple, San Jose, CA, USA).

\section{Establishment of the Animal Model}

All procedures were carried out according to protocols approved by the Institutional Committee for Use and Care of Laboratory Animals of Zhengzhou University and compliance with the "Guide for the Care and Use of Laboratory Animals". Subrenal capsule models were established as reported previously. ${ }^{21}$ Briefly, ESCC cells at a density of $1 \times 10^{6}$ were mixed with rat tail tendon collagen and incubated for $30 \mathrm{~min}$ of at $37^{\circ} \mathrm{C}$ to form a gel block that was kept in sterile Hanks fluid until xenotransplantation under the renal capsule of female NOD/SCID mice (4-6 weeks old), which were purchased from the Beijing Vital River Laboratory Animal Technology Co., Ltd. Mouse surgery was performed under sterile conditions. At week 1 post-operation, the animals were evaluated for
A

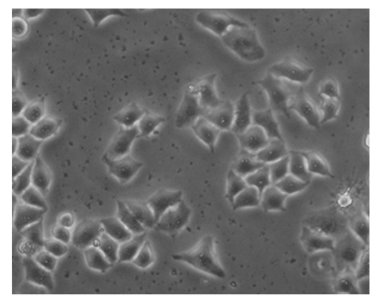

EC9706-I

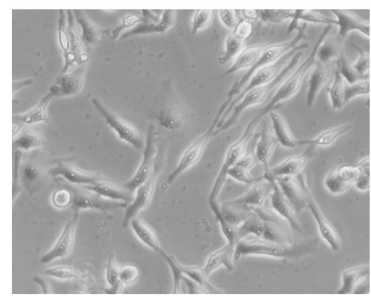

EC9706-I ${ }_{3}$
C

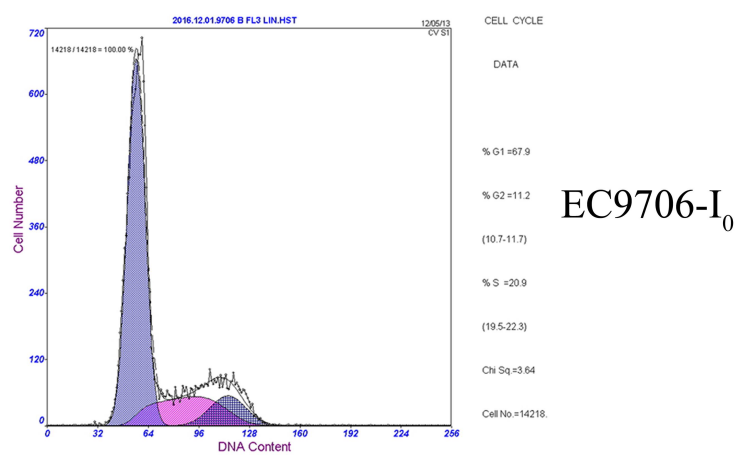

B
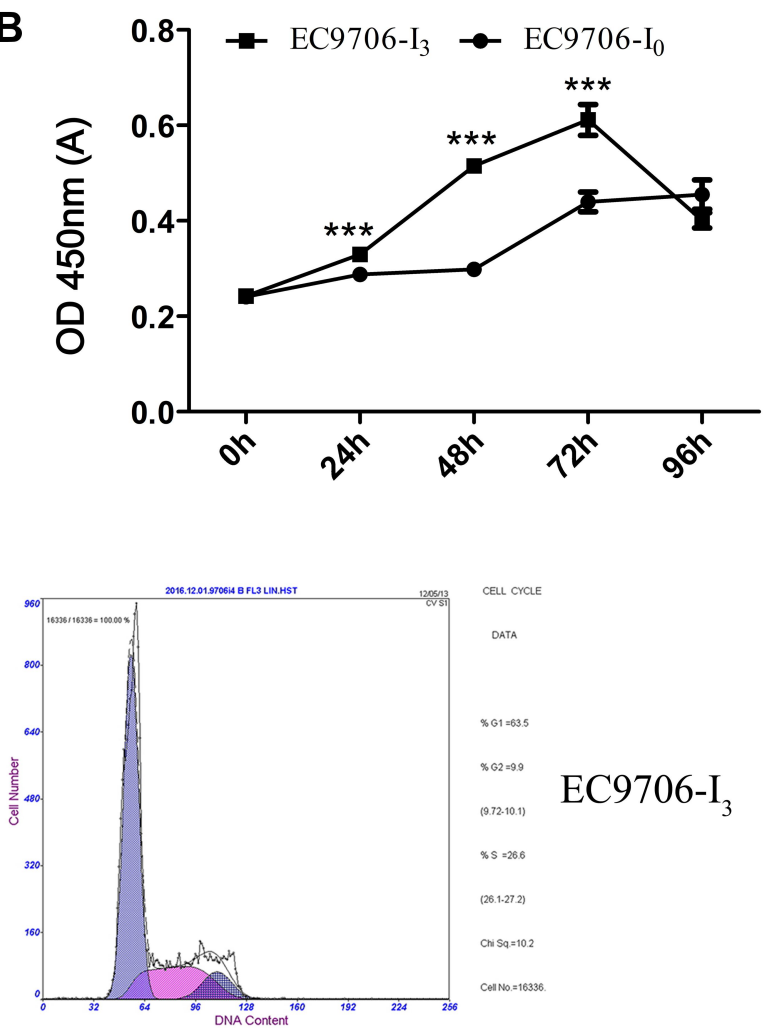

Figure I Screening of EC9706-I $\mathrm{I}_{0}$ and EC9706- $\mathrm{I}_{3}$ cells and identification of biological characteristics. (A) Morphology of EC9706-I0 and EC9706- $\mathrm{I}_{3}$ cells screened by three Transwell assays. (B) Number of metabolically active cells estimated by the CCK-8 assay at $0 \mathrm{~h}, 24 \mathrm{~h}, 48 \mathrm{~h}, 72 \mathrm{~h}$, and $96 \mathrm{~h}$ post-culture. (C) Cell cycle distribution assayed by flow cytometry. $* * *$ Indicates significant difference at $\mathrm{P}<0.001$. 
Table I DNA Content of EC9706-I0 and EC9706-I $\mathrm{I}_{3}$ Cells in Different Phases of Cell Cycle

\begin{tabular}{|l|l|l|l|l|}
\hline \multirow{2}{*}{ Groups } & \multicolumn{4}{|l|}{ DNA Content (\%) } \\
\cline { 2 - 5 } & $\mathbf{G}_{\mathbf{0}} / \mathbf{G}_{\mathbf{1}}$ & $\mathbf{S}$ & $\mathbf{G}_{\mathbf{2}} \mathbf{M}$ & PI \\
\hline EC9706-I $_{0}$ & 67.9 & 20.9 & 11.2 & 32.1 \\
EC9706-I $_{3}$ & 63.5 & 26.6 & 9.9 & 36.5 \\
\hline
\end{tabular}

Abbreviation: $\mathrm{Pl}$, proliferation index.

tumor growth using a live animal imaging system in conjunction with bioluminescent imaging. At week 14 post-operation, all mice were euthanised, tumors and organs were collected, photographed and fixed for histopathological evaluation.

\section{Hematoxylin and Eosin Staining}

Histopathology of the tumors and organs was assessed by a hematoxylin and eosin staining kit (Beyotime), according to the manufacturer's instructions. The results were evaluated by a pathologist.

\section{Statistical Analysis}

GraphPad Prism 8.0 (GraphPad, La Jolla, CA, USA) was used for statistical analysis. Quantitative data were presented as mean \pm standard error. Significant differences between groups were identified by Student's $t$-test at $P<0.05$.

\section{Results}

\section{EC9706-I ${ }_{3}$ Cells Exhibit a Rapid Proliferation Ability}

Compared with EC9706- $\mathrm{I}_{0}$ cells, EC9706- $\mathrm{I}_{3}$ cells did not show cell-cell contact and had a spindle-shaped, stretched fibroblast-like appearance with increased pseudopodia (Figure 1A). Besides, the proliferation ability of EC9706- $\mathrm{I}_{3}$ cells was significantly higher $(P<0.001)$ than that of EC9706- $\mathrm{I}_{0}$ cells at $24 \mathrm{~h}, 48 \mathrm{~h}$, and $72 \mathrm{~h}$ post-culturing (Figure 1B). The cell cycle distribution showed that EC9706- $\mathrm{I}_{3}$ cells exhibited a longer $\mathrm{S}$ phase but shorter $\mathrm{G}_{0}$ $/ \mathrm{G}_{1}$ phase with a concomitantly larger proliferation index compared with EC9706- $\mathrm{I}_{0}$ cells (Figure 1C and Table 1).

A

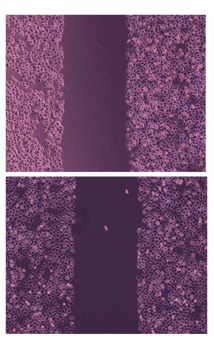

Oh

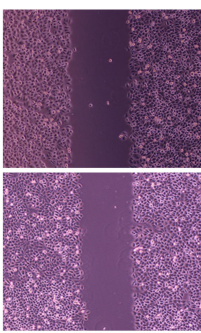

$24 \mathrm{~h}$

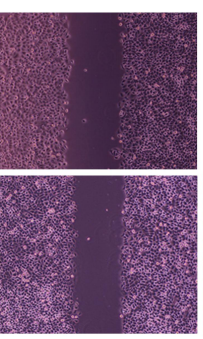

$48 \mathrm{~h}$

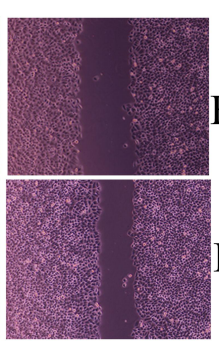

$72 \mathrm{~h}$
B

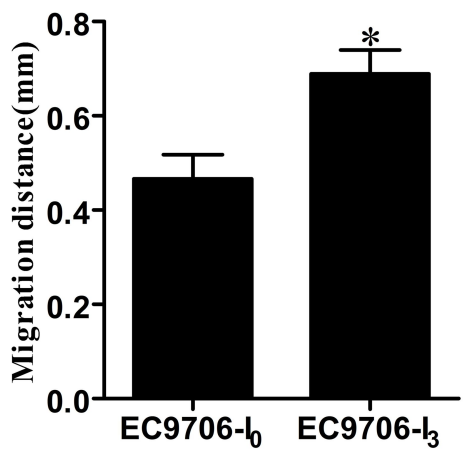

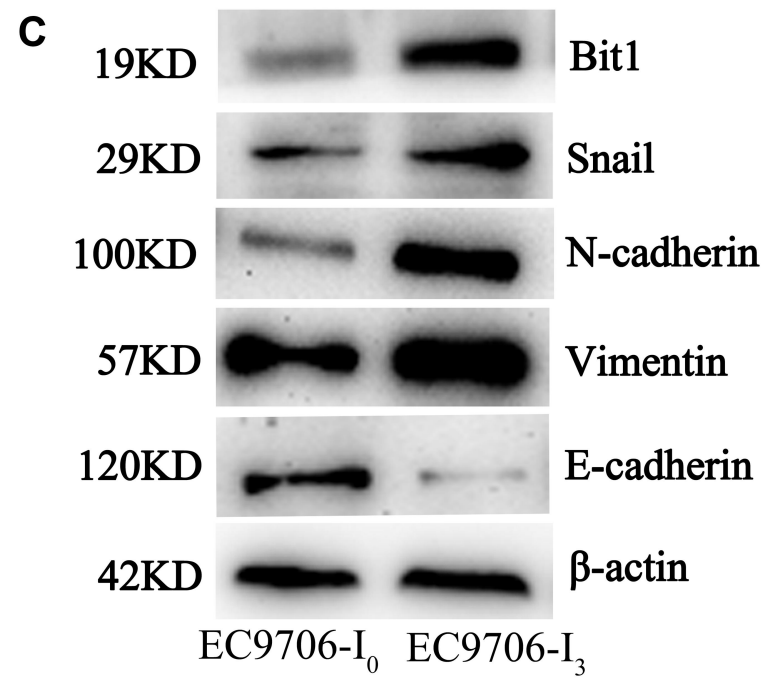

D

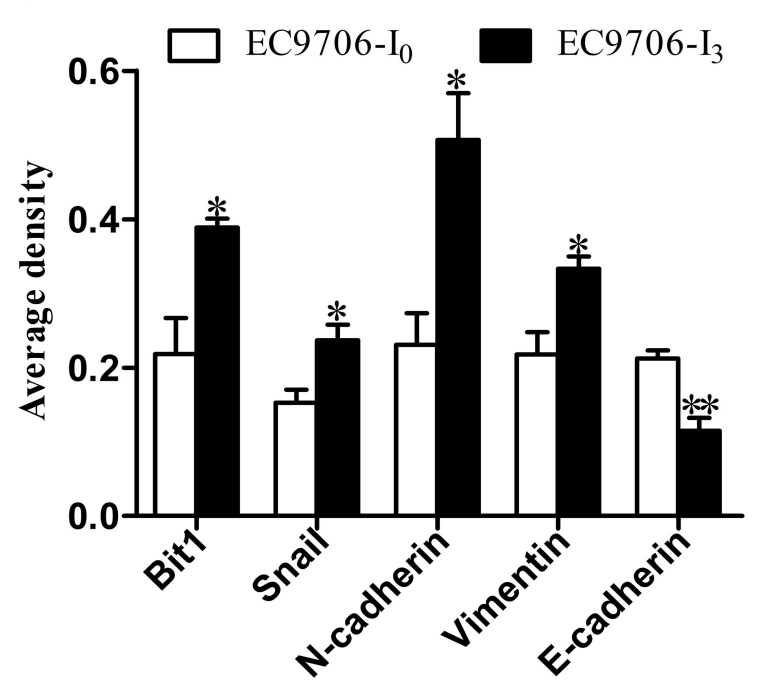

Figure 2 Migratory ability and phenotype of EC9706- $I_{3}$ and EC9706-I $I_{0}$ cells. (A) Migration ability of EC9706- $I_{0}$ and EC9706-I $I_{3}$ cells by wound healing assay. (B) Migrative

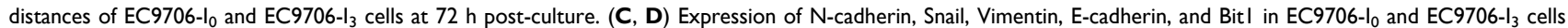
estimated by Western blot. All values are presented as mean \pm standard error $(\mathrm{SE})$. ${ }^{*}$ and $* *$ indicate significant differences at $\mathrm{P}<0.05$ and $\mathrm{P}<0.0 \mathrm{I}$, respectively. 
These data suggested that the novel ESCC cell line obtained by Transwell assay had a rapid proliferation ability.

\section{EC9706-I $I_{3}$ Cells Sustained a Mesenchymal Phenotype}

A stepwise study of the wound healing assay showed that the migration distance of EC9706- $\mathrm{I}_{0}$ cells was significantly lower $(P<0.05)$ than that of EC9706- $\mathrm{I}_{3}$ cells at $72 \mathrm{~h}$ post-culturing (Figure 2A and B). Western blot confirmed that N-cadherin, Vimentin, Snail and Bit1 expression was significantly upregulated $(\mathrm{P}=0.0221, \mathrm{P}=0.0273, \mathrm{P}=0.0372, \mathrm{P}=0.0272$, respectively) in EC9706- $\mathrm{I}_{3}$ cells compared with that in EC9706- $\mathrm{I}_{0}$ cells (Figure $2 \mathrm{C}$ and $\mathrm{D}$ ), whereas E-cadherin expression was significantly downregulated $(\mathrm{P}=0.0091)$. Our data suggested that EC9706-I $\mathrm{I}_{3}$ cells exhibited highly invasive ability with an obvious mesenchymal phenotype.

\section{EC9706-I 3 Cells Showed Relatively Low Chemosensitivity}

Our results showed that the chemosensitivity of EC9706- $\mathrm{I}_{3}$ cells to 5-FU, ADM, and DDP (Figure 3A-C) was reduced compared with that of EC9706- $\mathrm{I}_{0}$ cells. Specifically, the IC50 values of EC9706- $\mathrm{I}_{3}$ cells were higher than those of EC9706- $\mathrm{I}_{0}$ cells; $3.675 \pm 0.8386$ vs $0.9493 \pm 0.3003(\mathrm{P}=$ $0.0378)$ for $5-\mathrm{FU}, 1.229 \pm 0.3309$ vs $0.3273 \pm 0.0653(\mathrm{P}=$ $0.0557)$ for $\mathrm{ADM}$, and $5.137 \pm 0.6403$ vs $3.190 \pm 0.1147$ $(\mathrm{P}=0.1011)$ for DDP (Figure 3D-F). These data indicated that the high invasiveness of EC9706- $\mathrm{I}_{3}$ cells clearly reduced the sensitivity to 5 -FU.

\section{Rapid Proliferation Ability Triggered in the EC9706-I ${ }_{3}$ Cell Xenografted Mice}

EC9706- $\mathrm{I}_{0}$ and EC9706- $\mathrm{I}_{3}$ cells were transplanted beneath the renal capsule of five NOD/SCID mice. The rich supply of blood under subrenal capsule was conducive to the invasion and metastasis of cancer cells. As shown in Figure 4A, the tumorigenesis rate was $100 \%$, and the tumors formed by EC9706- $\mathrm{I}_{0}$ cells grew more slowly than those formed by EC9706- $\mathrm{I}_{3}$ cells at weeks 3-14 post-operation. At d 17 post-operation, the tumor specimens of the EC9706- $\mathrm{I}_{3}$ xenograft were covered by prominent vasoganglia on the renal surface (Figure 4B).
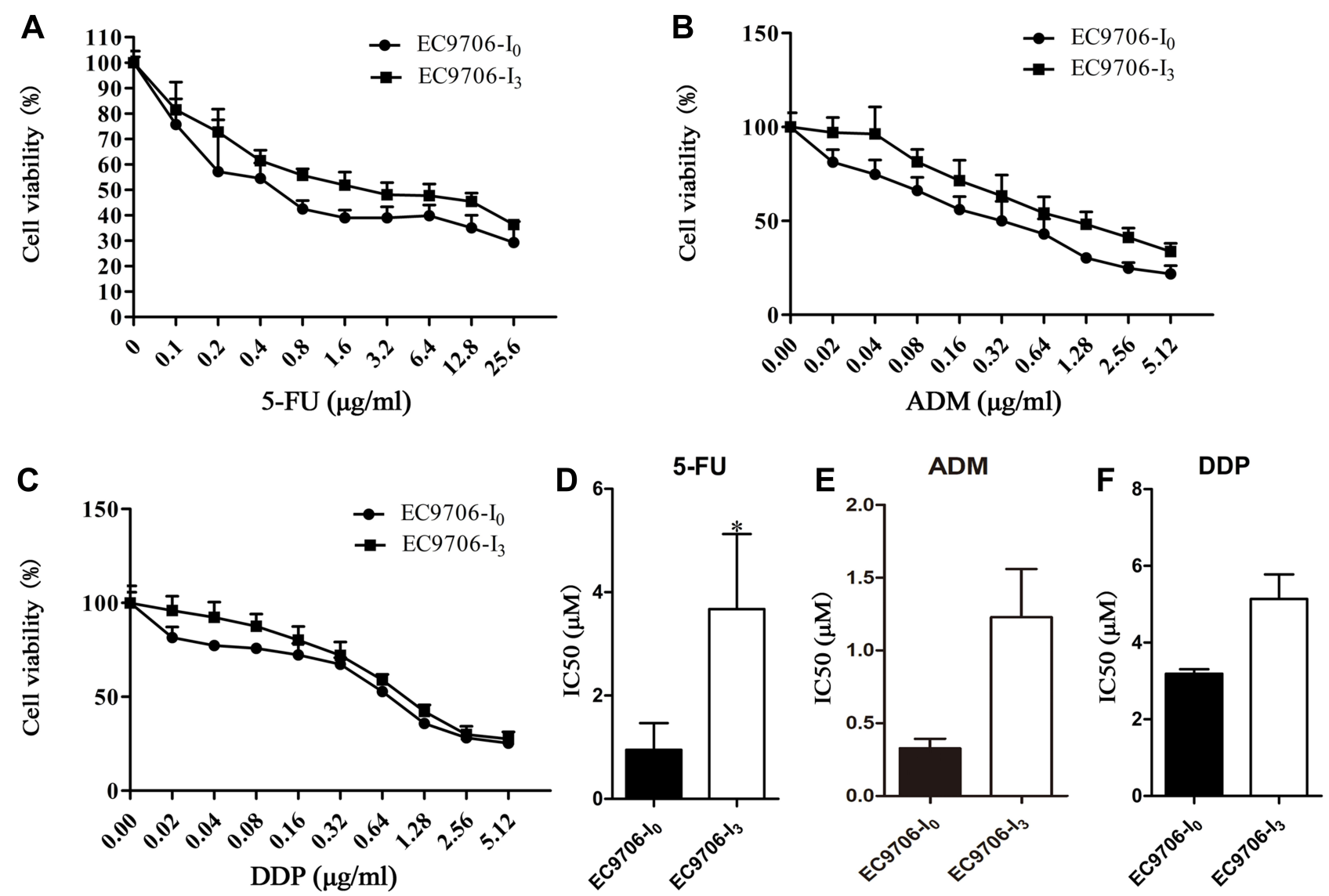

Figure 3 Chemosensitivity of EC9706-I $I_{0}$ and EC9706-I $I_{3}$ cells detected by CCK-8 assay. (A-C) Viability of EC9706-I and EC9706-I $I_{3}$ cells at different concentrations for 5-fluorouracil (5-FU), doxorubicin (ADM), and cisplatin (DDP). (D-F) IC50 of EC9706-I and EC9706-I 3 cells for 5-FU, ADM, and DDP. *Indicates significant difference at P < 0.05 . 
A

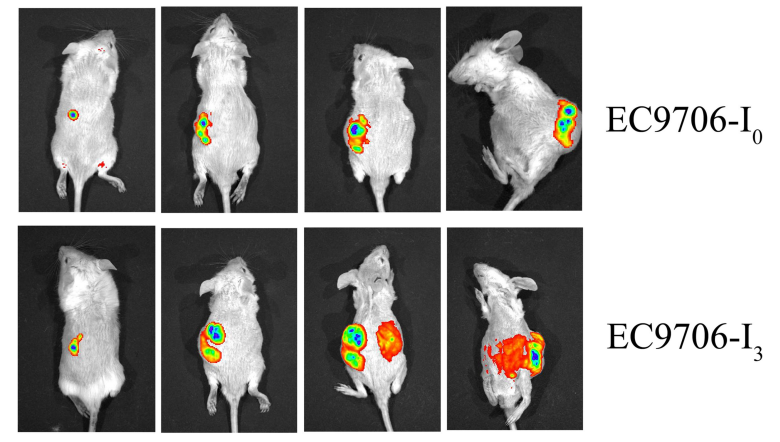

B

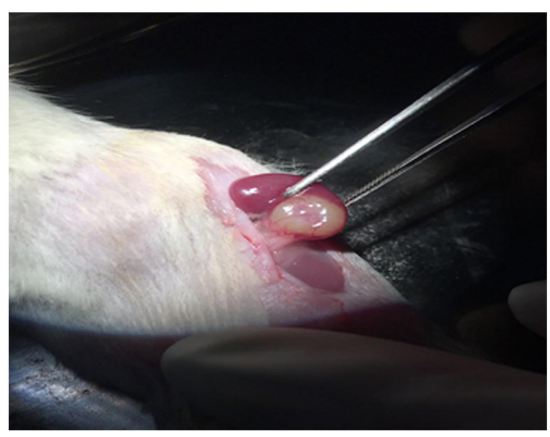

C

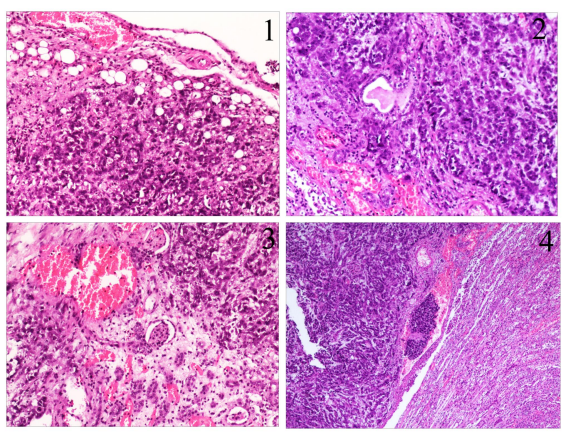

Figure 4 Subrenal capsule xenograft tumor model. (A) Live animal imaging for assessing tumourigenicity and tumor growth of EC9706- $\mathrm{I}_{0}$ and EC9706- $\mathrm{I}_{3}$ cells at weeks 3, 8, and 14 post-operation. (B) Tumor specimen of EC9706-I $\left.\right|_{3}$ xenograft tumors at day 17 post-operation. (C) Tumor metastasis in the subrenal capsule model using EC9706-1 ${ }_{3}$ cells: I) tumor cells grown under the renal capsule and gradually invaded into the renal tissue; 2 ) tumor cells gradually invaded and wrapped around glomerulus and renal tubules; 3 ) tumor cells gradually approached the renal vessels and invaded the vascular system; 4) tumor cells invaded the vascular system, survived and stayed, formed tumor thrombus, and metastasized to other organs by blood vessels.

The tumor beneath the renal capsule gradually invaded into the inner kidney tissues and then reached the glomeruli of the kidney and nephric tubule (Figure 4C). Finally, the tumor reached the vasculature of the kidney (Figure 4C). Only two mice died accidentally due to anesthesia, whereas the rest were euthanized after the end of the experimental period. No life-threatening postoperative complications were identified. These results suggested that the renal capsule model of ESCC cells was successfully established and had high proliferative potential.

\section{EC9706-I 3 Cells Displayed High Distant Metastatic Potential}

Pathological results confirmed that distant metastasis occurred in the EC9706- $\mathrm{I}_{3}$ xenograft model, and the metastatic site of the EC9706- $\mathrm{I}_{3}$ model contained the kidney, heart, liver, lung, spleen, and pancreas (Figure 5). In contrast, the distant metastasis rate of the EC9706- $\mathrm{I}_{0}$ model was $40 \%$, and the metastatic site included only the kidney and heart (Figure 5 and Table 2). These findings suggested that an animal metastatic model of ESCC subrenal capsule was successfully established, providing a novel platform for further exploring metastasis mechanisms.

\section{Discussion}

Previous studies revealed that animal models are essential for studying anti-tumor drug efficacy and toxicity as well as deciphering gene function in a majority of tumors. ${ }^{22-29}$ The subcutaneous grafting model and intravenous injection were mostly used to explore the efficacy of drug and gene function in ESCC; however, both models have major drawbacks such as low success rates, lack of metastasis, and dissemination or intravasation of tumor cells. ${ }^{19,30}$ The subrenal capsule can provide a positive interstitial fluid pressure and a high rate of blood flow, ${ }^{31}$ and thus it is ideal for establishing an animal model. Given the current internal nature of ESCC cell lines available without high invasion ability, it is very necessary to establish the highly invasive ESCC cell lines. Here, we screened EC9706- $\mathrm{I}_{3}$ cells using a Transwell assay and identified their biological characteristics. We further established a renal capsule model of ESCC cells, in which tumor cells displayed rapid proliferation ability and spontaneous distant metastatic potential. Therefore, our results will highly benefit the basic research and preclinical drug testing for ESCC.

Compared with EC9706- $\mathrm{I}_{0}$, the newly established cell line, EC9076- $\mathrm{I}_{3}$, exhibited high invasive ability, rapid proliferation, and reduced chemosensitivity for 5-FU, but not to DDP and ADM. Previous studies demonstrated that cell invasion and metastasis are tightly associated with the epithelial-mesenchymal transition process in various tumors. ${ }^{32-36}$ Notably, Bit1 expression is positively correlated with the invasion of ESCC cells in our publication. ${ }^{17}$ Therefore, in the present study, we studied the expressions of N-cadherin, Vimentin, Snail, and Bit1 in EC9706- $\mathrm{I}_{0}$ and EC9706- $\mathrm{I}_{3}$ cells and found that the latter harbored higher protein levels than the former, suggesting that the cell subpopulation was highly invasive, exhibited a mesenchymal 

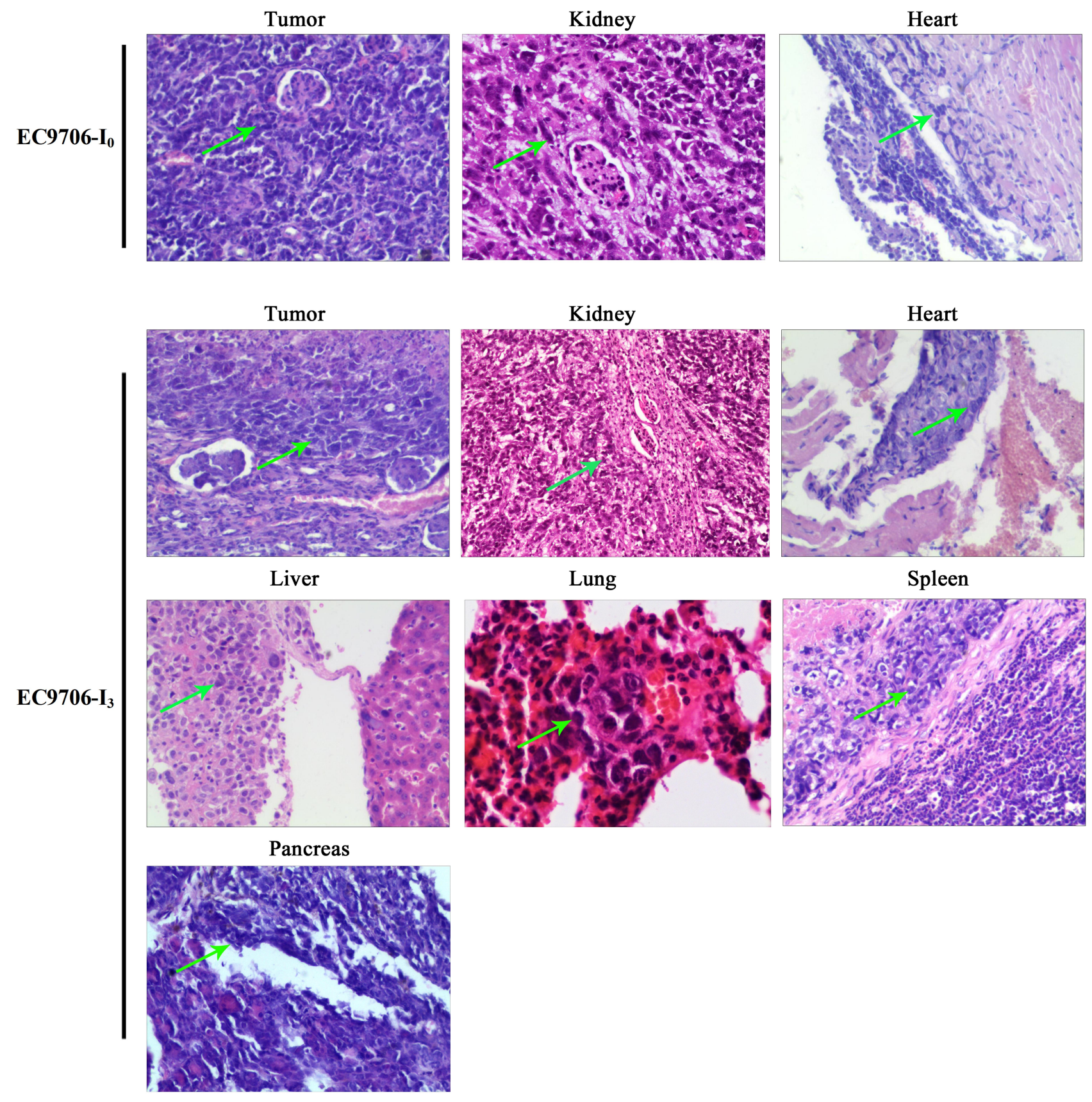

Figure 5 Tumor cells metastasis in the EC9706 xenograft subrenal capsule model visualized by hematoxylin and eosin staining. Green arrow, tumor cells metastasized to other organs.

phenotype, and thus, could be ideal for further exploring the molecular mechanisms of ESCC metastasis.

In past studies, subcutaneous xenograft and orthotopic models were employed to evaluate the efficacy of antitumor drugs in esophageal carcinoma. ${ }^{9,16,37,38}$ The strategy of implanting tumors beneath the renal capsule was developed for the rapid screening of chemotherapeutic agents. ${ }^{21}$ However, currently, there is no report of a high spontaneous metastatic model of ESCC using renal capsule technology.
Here, we utilized a highly aggressive EC9706- $\mathrm{I}_{3}$ cell line to establish a metastatic model by renal capsule technology. We found that the tumorigenesis rate was $100 \%$ but tumor growth by $\mathrm{EC} 9706-\mathrm{I}_{3}$ cells was more rapid than that by EC9706- $\mathrm{I}_{0}$ cells. Besides, distant metastasis occurred in EC9706- $\mathrm{I}_{3}$-derived tumors, and the metastatic site contained the lung, heart, liver, pancreas and spleen, whereas the distant metastasis rate of EC9706- $\mathrm{I}_{0}$ models was $40 \%$, and metastatic site was only restricted to heart. 
Table 2 Metastatic Sites, Tumorigenesis Rate, and Distant Metastatic of EC9706-I0 and EC9706-I $\mathrm{I}_{3}$ Cells in Mice

\begin{tabular}{|l|l|l|l|l|l|}
\hline Groups & $\begin{array}{l}\text { No. of } \\
\text { Mice }\end{array}$ & $\begin{array}{l}\text { Distant Metastatic } \\
\text { Number }\end{array}$ & Metastatic Sites & $\begin{array}{l}\text { Tumorigenesis } \\
\text { Rate (\%) }\end{array}$ & $\begin{array}{l}\text { Distant Metastatic } \\
\text { Rate (\%) }\end{array}$ \\
\hline EC9706-I & 5 & 2 & $\begin{array}{l}\text { Kidney and heart } \\
\text { Kidney, heart, liver, lung, pancreas, } \\
\text { and spleen }\end{array}$ & 100 & 40 \\
100 & 80 \\
\hline
\end{tabular}

Overall, the operational procedure was simple, the wound healing was accelerated, no infection occurred, and the model had a short establishment period. Thus, the chances for post-operational complications or mortality associated were relatively low. Moreover, the cells were inoculated on one of the renal capsules, and thus, the other can be used for regular functioning. The data supported that our animal model might provide an ideal platform for further exploring the molecular mechanisms of ESCC metastasis.

\section{Conclusions}

In conclusion, we established a highly invasive ESCC cell line with an obvious mesenchymal phenotype as well as a spontaneous and distant metastatic potential, which could be used to develop an animal model for studying ESCC. Overall, our model can serve as a platform for elucidating the underlying molecular mechanisms of ESCC metastasis and testing the efficacy of antimetastatic drugs.

\section{Funding}

This research was supported by the Natural Science Foundation of Henan Province (212300410393) and the High School Key Research Projects of Henan Province (20A310021).

\section{Disclosure}

The authors declared no competing conflicts of interest with respect to the study, authorship, and/or publication of this article.

\section{References}

1. Abnet CC, Arnold M, Wei W-Q, et al. Epidemiology of esophageal squamous cell carcinoma. Gastroenterology. 2018;154(2):360-373. doi:10.1053/j.gastro.2017.08.023

2. Blot WJ, Li JY. Some considerations in the design of a nutrition intervention trial in Linxian, People's Republic of China. Natl Cancer Inst Monogr. 1985;69:29-34.

3. Lin Y, Totsuka Y, Shan B, et al. Esophageal cancer in high-risk areas of China: research progress and challenges. Ann Epidemiol. 2017;27 (3):215-221. doi:10.1016/j.annepidem.2016.11.004
4. Pennathur A, Gibson MK, Jobe BA, et al. Oesophageal carcinoma. Lancet. $\quad 2013 ; 381(9864): 400-412 . \quad$ doi:10.1016/S0140-6736(12) 60643-6

5. Wu CC, Chen CJ. Esophageal carcinoma. $N$ Engl $J$ Med. 2015;372:1472. doi:10.1056/NEJMc1500692

6. Cekanova M, Rathore K. Animal models and therapeutic molecular targets of cancer: utility and limitations. Drug Des Devel Ther. 2014;8:1911-1921. doi:10.2147/DDDT.S49584

7. Tetreault MP. Esophageal cancer: insights from mouse models. Cancer Growth Metastasis. 2015;8:37-46. doi:10.4137/CGM.S21218

8. Fujihara S, Kato K, Morishita A, et al. Antidiabetic drug metformin inhibits esophageal adenocarcinoma cell proliferation in vitro and in vivo. Int J Oncol. 2015;46:2172-2180. doi:10.3892/ijo.2015.2903

9. Ford SJ, et al. Deferasirox (ICL670A) effectively inhibits oesophageal cancer growth in vitro and in vivo. $\mathrm{Br} J$ Pharmacol. 2013;168:1316-1328. doi:10.1111/bph.12045

10. Dodbiba L, Teichman J, Fleet A, et al. Appropriateness of using patient-derived xenograft models for pharmacologic evaluation of novel therapies for esophageal/gastro-esophageal junction cancers. PLoS One. 2015;10(3):e0121872. doi:10.1371/journal.pone.0121 872

11. Zhou F, Wang S, Wang J, et al. PAQR3 Inhibits the Proliferation and tumorigenesis in esophageal cancer cells. Oncol Res Featuring. 2017;25(5):663-671. doi:10.3727/096504016X14761384026719

12. Li L-Y, Xie Y-H, Xie Y-M, et al. Ezrin Ser66 phosphorylation regulates invasion and metastasis of esophageal squamous cell carcinoma cells by mediating filopodia formation. Int J Biochem Cell Biol. 2017;88:162-171. doi:10.1016/j.biocel.2017.05.018

13. Liang Y, Chen X, Wu Y, et al. LncRNA CASC9 promotes esophageal squamous cell carcinoma metastasis through upregulating LAMC2 expression by interacting with the CREB-binding protein. Cell Death Differ. 2018;25(11):1980-1995. doi:10.1038/s41418018-0084-9

14. Hu T, Qi H, Li P, et al. Comparison of GFP-expressing imageable mouse models of human esophageal squamous cell carcinoma established in various anatomical sites.. Anticancer Res. 2015;35 (9):4655-4663.

15. Zhang J, luo A, Huang F, et al. SERPINE2 promotes esophageal squamous cell carcinoma metastasis by activating BMP4. Cancer Lett. 2020;469:390-398. doi:10.1016/j.canlet.2019.11.011

16. Gros SJ, Kurschat N, Dohrmann T, et al. Effective therapeutic targeting of the overexpressed HER-2 receptor in a highly metastatic orthotopic model of esophageal carcinoma. Mol Cancer Ther. 2010;9(7):2037-2045. doi:10.1158/1535-7163.MCT-10-0209

17. Fan T, Chen J, Zhang L, et al. Bit1 knockdown contributes to growth suppression as well as the decreases of migration and invasion abilities in esophageal squamous cell carcinoma via suppressing FAK-paxillin pathway. Mol Cancer. 2016;15(1):23. doi:10.1186/s12943-016-0507-5

18. Zaidi AH, Saldin LT, Kelly LA, et al. MicroRNA signature characterizes primary tumors that metastasize in an esophageal adenocarcinoma rat model. PLoS One. 2015;10(3):e0122375. doi:10.1371/ journal.pone. 0122375

19. Liu DS, Hoefnagel SJM, Fisher OM, et al. Novel metastatic models of esophageal adenocarcinoma derived from FLO-1 cells highlight the importance of E-cadherin in cancer metastasis. Oncotarget. 2016;7(50):83342-83358. doi:10.18632/oncotarget.13391 
20. Han Y, Wei F, Xu X, et al. [Establishment and comparative genomic hybridization analysis of human esophageal carcinomas cell line EC9706]. Zhonghua Yi Xue Yi Chuan Xue Za Zhi = Zhonghua Yixue Yichuanxue Zazhi = Chinese Journal of Medical Genetics. 2002;19(6):455-457.

21. Bogden AE, Haskell PM, LePage DJ, et al. Growth of human tumor xenografts implanted under the renal capsule of normal immunocompetent mice. Exp Cell Biol. 1979;47(4):281-293. doi:10.1159/000162947

22. Costa MJ, Kudaravalli J, Liu W-H, et al. A mouse model for evaluation of efficacy and concomitant toxicity of anti-human CXCR4 therapeutics. PLoS One. 2018;13(3):e0194688. doi:10.1371/journal.pone.0194688

23. Mori M, Kaneko N, Ueno Y, et al. Gilteritinib, a FLT3/AXL inhibitor, shows antileukemic activity in mouse models of FLT3 mutated acute myeloid leukemia. Invest New Drugs. 2017;35(5):556-565. doi:10.1007/s10637-017-0470-z

24. Falah M, Rayan M, Rayan A, et al. A novel paclitaxel conjugate with higher efficiency and lower toxicity: a new drug candidate for cancer treatment. Int J Mol Sci. 2019;20(19):20. doi:10.3390/ijms20194965

25. Tao Y, Wang R, Lai Q, et al. Targeting of DDR1 with antibody-drug conjugates has antitumor effects in a mouse model of colon carcinoma. Mol Oncol. 2019;13(9):1855-1873. doi:10.1002/1878-0261.12520

26. Ireson CR, Alavijeh MS, Palmer AM, et al. The role of mouse tumour models in the discovery and development of anticancer drugs. $\mathrm{Br}$ J Cancer. 2019;121(2):101-108. doi:10.1038/s41416-019-0495-5

27. Zhang X, Fan T, Li S, et al. C-Phycocyanin elicited antitumor efficacy via cell-cycle arrest, apoptosis induction, and invasion inhibition in esophageal squamous cell carcinoma. J Receptors Signal Transduction. 2019;39 (2):114-121. doi:10.1080/10799893.2019.1638400

28. Rosenbluh J, Nijhawan D, Cox A, et al. $\beta$-Catenin-Driven cancers require a YAP1 transcriptional complex for survival and tumorigenesis. Cell. 2012;151(7):1457-1473. doi:10.1016/j.cell.2012.11.026

29. Daubon T, Léon C, Clarke K, et al. Deciphering the complex role of thrombospondin-1 in glioblastoma development. Nat Commun. 2019;10(1):1146. doi:10.1038/s41467-019-08480-y
30. van Weerden WM, de Ridder CM, Verdaasdonk CL, et al. Development of seven new human prostate tumor xenograft models and their histopathological characterization. Am J Pathol. 1996;149 (3):1055-1062.

31. Ott CE, Knox FG. Tissue pressures and fluid dynamics in the kidney. Fed Proc. 1976;35(8):1872-1875.

32. Mittal V. Epithelial mesenchymal transition in tumor metastasis. Ann Re Pathol. 2018;13(1):395-412. doi:10.1146/annurev-pathol-020117043854

33. Lu W, Kang KY. Epithelial-mesenchymal plasticity in cancer progression and metastasis. Dev Cell. 2019;49(3):361-374. doi:10.1016/ j.devcel.2019.04.010

34. Pastushenko I, Blanpain C. EMT transition states during tumor progression and metastasis. Trends Cell Biol. 2019;29(3):212-226. doi:10.1016/j.tcb.2018.12.001

35. Tsubakihara Y, Moustakas A. Epithelial-mesenchymal transition and metastasis under the control of transforming growth factor beta. Int J Mol Sci. 2018;19(11):19. doi:10.3390/ijms19113672

36. Chaffer CL, San Juan BP, Lim E, et al. EMT, cell plasticity and metastasis. Cancer Metastasis Rev. 2016;35:645-654. doi:10.1007/ s10555-016-9648-7

37. Drenckhan A, Kurschat N, Dohrmann T, et al. Effective inhibition of metastases and primary tumor growth with CTCE-9908 in esophageal cancer. $J$ Surg Res. 2013;182(2):250-256. doi:10.1016/j.jss.2012.09.035

38. Kresty LA, Weh KM, Zeyzus-Johns B, et al. Cranberry proanthocyanidins inhibit esophageal adenocarcinoma in vitro and in vivo through pleiotropic cell death induction and PI3K/AKT/mTOR inactivation. Oncotarget. 2015;6(32):33438-33455. doi:10.18632/ oncotarget.5586
OncoTargets and Therapy

\section{Publish your work in this journal}

OncoTargets and Therapy is an international, peer-reviewed, open access journal focusing on the pathological basis of all cancers, potential targets for therapy and treatment protocols employed to improve the management of cancer patients. The journal also focuses on the impact of management programs and new therapeutic

\section{Dovepress}

agents and protocols on patient perspectives such as quality of life, adherence and satisfaction. The manuscript management system is completely online and includes a very quick and fair peer-review system, which is all easy to use. Visit http://www.dovepress.com/ testimonials.php to read real quotes from published authors. 